\title{
Efficiency of University Course during the Covid-19 Pandemic
}

\author{
Martin Vejačka \\ Faculty of Economics, Technical University of Košice, Nemcovej 32, Košice, Slovakia
}

\begin{abstract}
The education in this field of electronic banking has to adapt to rapid progress in technologies used for provision of banking services. The paper aims to shortly present the course of Electronic Services in Banking and to measure and compare the efficiency of education in the course before and during the Covid-19 pandemic. The efficiency of the educational process in the course was measured as learning gain by comparing pre-course and post-course tests' results using absolute gain, relative gain, and class average normalized gain during a period of five years. The education in the course was evaluated as effective in all observed cases. The additional surveys were conducted before and after the course completion detecting positive shifts in students' knowledge and their adoption of electronic services in banking.
\end{abstract}

Keywords - Efficiency of education, University course, Covid-19 Pandemic, Electronic banking, Learning gain.

\section{Introduction}

The spread of new coronavirus and the outbreak of the Covid-19 pandemic caused multiple problems in virtually all areas of human activity.

The pandemic of such extent did not affect our society for approximately one hundred years, since the pandemic of Spanish flu was spreading in years from 1918 to 1920 .

DOI: 10.18421/TEM104-13

https://doi.org/10.18421/TEM104-13

Corresponding author: Martin Vejačka, Faculty of Economics, Technical University of Košice, Nemcovej 32, Košice, Slovakia.

Email: martin.vejacka@tuke.sk

Received: 02 August 2021.

Revised: 19 September 2021.

Accepted: 25 September 2021.

Published: 26 November 2021.

(c) BY-Nc-ND (C) 2021 Martin Vejačka; published by UIKTEN. This work is licensed under the Creative Commons Attribution-NonCommercial-NoDerivs 4.0 License.

The article is published with Open Access at www.temjournal.com
This situation could not be predicted and therefore no one could prepare for it. The measures for prevention of Covid-19 spread affected also the educational process at the universities. In many cases, face-to-face lectures or seminars were replaced by online education, similarly as at lower levels of the educational system.

University courses had to adapt to these conditions to provide education at the same quality in comparison with the classical forms of education provided in their pre-pandemic iterations. Now emerges the need for measuring and comparing the efficiency of the educational process in the course with regard to pre-pandemic and pandemic conditions.

This paper considers the course dedicated to electronic banking and related electronic services. The course is named Electronic Services in Banking (ESB) and deals with education in the field of electronic banking of students of economics. Data about the educational process in this course were gathered, the efficiency of education was measured and used for comparison of pre-pandemic years (2017 - 2019) and pandemic periods of the course (2020 and 2021).

\section{The Course Introduction}

The development of information and communication technologies (ICT) allowed the provision of banking services in new ways. Over decades rapidly increasing availability of computers and mobile devices to the broad population enabled to provide banking services using electronic media. Currently, electronic banking is a dominant form of providing banking services virtually worldwide. Electronic services in banking are designed to be more time and cost-effective than classical banking services provided in brick-and-mortar branches [1]. Furthermore, electronic banking services are still developed into newer forms as new ICTs emerge. The communication between providers of banking services and their users using electronic banking services is smoother and faster than in traditional ways. However, the introduction of electronic banking services and their continual provision 
invokes additional costs compared to the provision of banking services only in the traditional way [2]. Also, the continuous development of electronic banking forms induces expenditures on development.

Education in the area of electronic services used in banking has to adapt to these rapid changes of technologies virtually every year. The course named Electronic Services in Banking (ESB) provides education for students of finance, banking and investment in this field for several years already. The content of the ESB course is continuously developed and adjusted to reflect modern trends in electronic banking and related services. Older forms of electronic banking (such as Home banking, GSM banking, and others) were omitted from the course curricula overtime during the course provision as they became outdated. On the other hand, some new topics (e.g. Smart banking/Mobile banking) were introduced during the years of the ESB course provision. During the non-pandemic year, the ESB course comprises both practical exercises and theoretical seminars. The educational process within the course uses eLearning principles and is supported by the learning management system (LMS) Moodle. It is an open-source eLearning platform that provides a secure and robust learning environment for its users [3]. LMS Moodle is used in the educational process of many other courses at our institution as it serves as a standard eLearning platform [4].

The ESB course is focused on the introduction of various forms of electronic banking with emphasis on their security and safety, while it supports the process of building trust in electronic banking services [5]. Multiple forms of authentication and authorization in electronic services are presented and discussed in the course with the emphasis on the digital signature as it is also usable for authorization of electronic documents, what allows overlap of the ESB into other related areas (e.g. e-government). The safety rules of e-services usage are emphasized as their adherence is an important part of security [6]. In addition, the security of electronic banking is also an important factor of electronic banking acceptance [7]. Alongside, awareness about electronic banking and the amount of information about it positively influence the adoption of electronic banking [8], [9]. Not least, the perceived usefulness of electronic banking services may positively affect their adoption [5]. Consequently, all mentioned aspects are reflected within the ESB course to support participants' acceptance of electronic banking.

Within the course of Electronic Services in Banking multiple information and communication technologies are used. Besides LMS Moodle, the course is supported by the virtual bank (in the course called Electronic Online Bank - EOB), which is built on the older banking software obtained as a gift to the faculty for educational uses. The virtual bank supports Internet banking and some older forms (that might be briefly mentioned as historical forms of ebanking developed into newer forms) and also allows electronic payments authorized by digital signatures. Current forms of electronic banking (e.g. Mobile banking, QR code payments, etc.) are presented and tried by students for educational purposes. Certification authority built on EJBCA open source certification authority is also used within the ESB course to support the use of digital signature in the field of electronic communication within electronic banking [10]. For managing the digital signature certificates in personal computers serves the GPG4win open-source software. OpenKeychain is used for similar purposes in mobile devices. Several subjects are discussed in the form of students' essays as a mandatory assignment in the course. Students should include their experience with the topic within the essay.

Smart mobile devices emerged and developed extremely in the last two decades. Their growing penetration reflected also banking institutions by introducing electronic banking services tailored to be used in many forms of these mobile devices (e.g. personal digital assistants, early mobile phones to more sophisticated smartphones, tablets, and similar devices, etc.). Also in several other areas (such as electronic commerce), mobile devices started to apply [11]. Various forms of electronic banking developed over time were called mobile banking as the technologies of mobile devices rapidly developed. Currently, mobile banking denotes the electronic banking form available in smart mobile devices via dedicated application using online data transfers over the internet. Now it is the most used form of electronic banking [6]. Mobile banking is not supported by our virtual bank and therefore, students are to use real bank's mobile banking application to perform the mandatory task of payment via mobile banking. Technically, obsolete forms of electronic banking, which were once referred to as mobile banking (e.g., WAP Banking, GSM banking), are briefly mentioned to demonstrate rapid development in this field. The principles of secure usage of mobile banking are presented to students to underline their role in building trust in electronic banking.

Also, electronic banking in traditional personal computers using an internet connection, usually referred to as Internet banking, is presented and demonstrated in the course of ESB using the virtual bank. Several possibilities of authorization and authentication (e.g. dynamically generated codes, digital signature, etc.) are practically presented and used by students. Students try out the realization of electronic payment using this type of electronic banking. Again, the emphasis is laid on the safety of 
its usage and the adherence to security rules when using Internet banking. Theoretical materials (including videos, figures, texts, etc.) regarding Internet banking are available to the course participants within LMS Moodle. Financial services potentially available in Internet banking of real-life banks (e.g. fund investments, loans, deposits) are mentioned.

Curricula of the ESB course includes also innovative electronic services related relevant to the banking field (e.g., p2p payments, contactless payments, cryptocurrencies, etc.). Students have to write an essay on topics related to any electronic service in banking and shortly present it to the other course participants within their class. These essays should reflect student's experience with a given topic or their opinion on it if they lack the experience. The topics of the essays are further discussed and essays themselves are available to students within the LMS Moodle allow any further discussion about them.

The security of electronic banking is the main focus of the ESB course. The rules of secure usage electronic services usage are introduced and emphasized. Several elements of authorization and authentication used in electronic banking are demonstrated within the course, namely: static passwords, dynamic codes, biometric security elements, digital signature. Their intrinsic level of security is compared. Additionally, the important role of limits (e.g. maximum payment amount, time limit of inactivity in application or browser) is noticed. Prevention of security breaches and forms of attacks on electronic banking are highlighted.

Digital signature has a specific position in the ESB course. It can serve as an authorization and authentication element within some forms of electronic banking services but also it can be used in secure communication and data interchange among banks and their clients. This role can digital signature fulfill also in other fields, for example in eGovernment. The terms of symmetric and asymmetric encryption, Public Key Infrastructure, and electronic signature legislation are explained in the ESB course. Participants generate their certificates for digital signing at the certification authority based on EJBCA open source certification authority managed by lecturers. The processes of digital signing and its verification are performed by students. Also, encryption and decryption of electronic documents using digital signature certificate are demonstrated. Multiple free software applications (Decrypto, OpenKeychain, GPG4win) for managing and usage of digital signature are used in the ESB course.

During the course, students fulfill the practical tasks using Mobile banking, Internet banking, and digital signature. In addition to that, they prepare and present their essay. The important parts of their evaluation are the pre-course and the post-course tests for assessment of their theoretical (and partially even practical) knowledge in the field of electronic banking. Conducting both pre-course and post-course tests allows measuring their study gains during the course.

\section{Literature Review}

Measuring and analyzing educational effectiveness is a subject of relatively broad discussion among professionals. Valle and Gomes [12] investigated educational effectiveness using statistical methods (regression and correlation analysis) to expose the importance of financial transfers in the area of education. Scheerens [13] explored educational effectiveness and ineffectiveness on lower levels of education (below university studies) and detected usage of innovative approaches in establishing educational effects by comparing schooling to (episodes of) non-schooling. Using the correlation between students' self-reports and objective measures of learning is questioned by some authors [14], and details that survey data would require further tests to be validated. This validation process could include comparing the results of self-reports against achievement data or measures of students' performance (e.g. tests' scores).

Vermunt et al. [15] suggested for measuring the educational efficiency the use of learning gain measurement and describing it as the difference between the skills, competencies, content knowledge, and personal development demonstrated at two points in time. Evans et al. [16] identified that learning gain measuring approaches should be integral to curriculum design and delivery and not extraneous to it. Willets [17] considers measuring the learning gain a policy solution to identifying the effective educational process at the university level. Identifying the learning gain in the course can be part of the decision-making process when considering university courses by students. Students are demanding increased levels of knowledge regarding potential university courses in order to make informed decisions regarding how best to invest their money, time, and opportunity. A comparison of the teaching quality delivered on different programs of study will be an important element of this decisionmaking process [18].

A basic requirement for measuring learning gain (within one institution or group of students) is that the methods employed produce comparable data. Perhaps the most robust method to achieve this is through longitudinal data, i.e. data on the same group of students over at least two points in time [19]. Longitudinal designs could cover several types of 
data, such as student grades, scores in other assessments, or self-reports [19]. Because of the usage of pre-course and post-course tests in the ESB course (i.e. two points in time), their comparison to express learning gain was the ideal choice. In general, it is hard to prove that a learning gain was invoked by an educational process [20]. There are disputes about the use of pre-course and post-course assessments for comparison [21]. In addition, it is tough to demonstrate the causality due to retention, natural maturation, or possible parallel training. Furthermore, it is difficult to create a control group for comparison with a group with an educational intervention [22]. However, comparing internal scores in the course is an objective and valid form of measuring the learning gain of course participants [23].

Several authors used class-average normalized gain to measure the effectiveness of a course in areas as natural sciences and engineering [24], [25]. Classaverage normalized gain $\langle\mathrm{g}\rangle$ represents the ratio of the whole group's performance to the maximum achievable improvement. Mathematically, it can be expressed as a fraction of maximum achievable precourse to post-course gain [20]. Educationalists may use this measure to reduce the confounding effects of pre-course knowledge (and other baseline characteristics), in that way reducing the need for a control group [26]. Class average normalized gain can be also pronounced as a metric of concepts that students averagely master, which they did not already know at the start of the class [27].

\section{Methodology}

When considering the fact, that in the course of Electronic Services in Banking pre-course and postcourse tests were conducted in the last five periods of the course, the evaluation and comparison of precourse and post-course tests' results using measures of learning gain are considered an appropriate method for assessing the effectiveness of the educational process in the course. The measures of absolute gain, relative gain, and class average normalized gain were used to express and measure this effectiveness.

Average gain ( $\mathrm{g}_{\text {avg }}$ ) is calculated as the average post-course score - average pre-course score achieved by students in a given year (1).

$\mathrm{g}_{\mathrm{avg}}=$ Avg post-course score - Avg pre-course score

Absolute gain (gabs) expresses the ratio between average gain and maximum score achievable in the test (in our case 100 points) (2).

$\mathrm{g}_{\mathrm{abs}}=$ Avg gain / Maximum score achievable

Relative gain $\left(\mathrm{g}_{\mathrm{rel}}\right)$ represents the increment of their scores in comparison with their early test results. It is calculated as average gain divided by average precourse score (3).

$\mathrm{g}_{\text {rel }}=$ Avg gain / Avg pre-course score

Finally, class average normalized gain $\langle\mathrm{g}\rangle$ is calculated as average gain divided by the maximum possible gain (4). The maximum possible gain is the maximum score achievable (in this case 100 points) decreased by the average pre-course score.

$\langle\mathrm{g}\rangle=$ Avg gain/ (100 - Avg pre-course score $)$

Using these measures, the effectiveness of the educational process within the course of Electronic Services in banking will be expressed. The anticipated result was that the education in the ESB course contributes to the significant knowledge gains of the students.

\section{Results}

The tests at the beginning of the course (serving as a pre-course test) and at the end of the course (postcourse test) are mandatory tasks for all students studying in the ESB course. Tests are conducted electronically using LMS Moodle. As the tests were mandatory tasks in the course, the sample represented a complete set of course graduates. Both these tests included 10 questions randomly selected from the set of 40 questions prepared by lecturers. All these questions from the field of electronic services in banking were designed to be of approximately the same difficulty for students. Table 1 contains the results of tests and their comparison.

Table 1. Comparison of pre-course and post-course test results during the period of 2017 - 2021

\begin{tabular}{||cccccccc||}
\hline \hline Year & $\mathrm{N}$ & $\begin{array}{c}\text { Pre-course test } \\
\text { scores }\end{array}$ & $\begin{array}{c}\text { Post-course test } \\
\text { scores }\end{array}$ & $\begin{array}{c}\mathrm{p} \\
\text { value }\end{array}$ & $\begin{array}{c}\text { Absolute gain } \\
\left(\mathrm{g}_{\mathrm{abs}}\right)\end{array}$ & $\begin{array}{c}\text { Relative gain } \\
\left(\mathrm{g}_{\text {rel }}\right)\end{array}$ & $\langle\mathrm{g}\rangle$ \\
2017 & 126 & $58.89 \% \pm 13.09 \%$ & $75.80 \% \pm 11.84 \%$ & 0.020 & $16.91 \%$ & $28.72 \%$ & $41.14 \%$ \\
2018 & 119 & $58.17 \% \pm 11.51 \%$ & $72.10 \% \pm 10.33 \%$ & 0.018 & $13.93 \%$ & $23.95 \%$ & $33.30 \%$ \\
2019 & 138 & $56.35 \% \pm 11.50 \%$ & $71.53 \% \pm 11.65 \%$ & 0.012 & $15.17 \%$ & $26.93 \%$ & $34.76 \%$ \\
2020 & 135 & $53.82 \% \pm 12.34 \%$ & $71.17 \% \pm 10.49 \%$ & 0.031 & $17.35 \%$ & $32.24 \%$ & $37.57 \%$ \\
2021 & 141 & $57.78 \% \pm 12.83 \%$ & $73.97 \% \pm 11.29 \%$ & 0.024 & $16.19 \%$ & $28.02 \%$ & $38.35 \%$ \\
Total & 659 & $57.01 \% \pm 12.25 \%$ & $72.94 \% \pm 11.12 \%$ & 0.021 & $15.93 \%$ & $27.94 \%$ & $37.06 \%$ \\
\hline \hline
\end{tabular}


The maximum score for both tests was $100 \%$. The data of the tests' results were gathered from consecutive 5 years of the ESB course periods from 2017 to 2021. In each year, over 100 tests (in both time points separately) were gathered, which satisfies the claim of Hair Jr et al. [28] that the minimum sample size is 50 and favorably 100 observations for most research situations.

The last two periods of the ESB course (in years 2020 and 2021) were affected by the Covid-19 pandemic. Valid pandemic prevention measures caused that face-to-face classes could not be conducted during the whole two iterations of the course. Nonetheless, the course of Electronic services in Banking was intended for full online availability for all participants.

During pre-pandemic years (2017 to 2019) tests were conducted within the face-to-face classes. In 2020 as the pandemic of Covid-19 disease accelerated, it was necessary to switch into the fully distant form using online learning. As the pandemic continued into 2021, also the following iteration of the course was conducted in the online education form. Lectures were conducted over Cisco Webex Meeting application. Furthermore, additional text and video materials were added to the course within LMS Moodle to support the self-education process of students. Additionally, participants had the option to consult with lecturers using email, online chat, or video calls if necessary.

Overall, 659 eligible tests in each of both groups (pre-course and post-course) were gathered during the period five years from 2017 to 2021 . If there was an uneven number of pre-course and post-course tests gathered in a particular year, only an equal number of tests was used for comparison to avoid twisting the results. In total, the mean test score significantly increased from $57.01 \%( \pm 12.25 \%)$ in the pre-course test to the resulting $72.94 \%$ ( \pm $11.12 \%)(p=0.021)$ mean score in the post-course test. The overall absolute gain was $19.93 \%$ and relative gain represented $27.94 \%$. The main measure of educational process's efficiency used in the analysis, the class average normalized gain $\langle\mathrm{g}\rangle$ was at the level of $37.06 \%$. According to [29] and [30], the educational process is effective if the class average normalized gain is above $30 \%$, what has been achieved overall in all five years altogether.

When considering results in the individual years the results were following. The mean test score in 2017 significantly raised from $58.89 \%( \pm 13.09 \%)$ in the pre-course test to the level of $75.80 \%( \pm 11.84 \%)$ $(\mathrm{p}=0.020)$ in the post-course test. The absolute gain in 2017 was measured at the level of $16.91 \%$ and the relative gain at $28.72 \%$. The class average normalized gain $\langle\mathrm{g}\rangle$ was at the level of $41.14 \%$.
In 2018 , the mean test score raised from $58.17 \%$ $( \pm 11.51 \%)$ of the pre-course test to $72.10 \%$ ( \pm $10.33 \%)(p=0.018)$ in the post-course test. The absolute gain in 2018 was $13.93 \%$ and the relative gain was $23.95 \%$. The class average normalized gain $\langle\mathrm{g}\rangle$ was $33.30 \%$.

The mean test score in 2019 substantially increased from $56.35 \%( \pm 11.50 \%)$ in the pre-course test to $71.53 \%( \pm 11.65 \%)(p=0.012)$ in the post-course test. The absolute gain in 2019 was $15.17 \%$ and relative gain was $26.93 \%$. The class average normalized gain $\langle\mathrm{g}\rangle$ was $34.76 \%$.

In the year 2020, the mean test score significantly raised from $53.82 \%( \pm 12.34 \%)$ in the pre-course test to $71.17 \%( \pm 10.49 \%)(p=0.031)$ in the post-course test. The absolute gain in 2020 was at the level of $17.35 \%$ and the relative gain was at the level of $32.24 \%$. The class average normalized gain $\langle\mathrm{g}\rangle$ was $37.57 \%$.

In 2021, the mean test score significantly increased from $57.78 \%( \pm 12.83 \%)$ in the pre-course test to $73.97 \%( \pm 11.29 \%)(p=0.024)$ in the post-course test. The absolute gain in 2021 was $16.19 \%$ and the relative gain was $28.02 \%$. The class average normalized gain $\langle\mathrm{g}\rangle$ was $38.35 \%$.

Consequently, the above-stated level of the effective educational process (i.e. class average normalized gain higher than $30 \%$ ) was recorded in each individual year within the ESB course. Therefore, the ESB course represented an effective form of education in the field of electronic services in banking.

The ESB course is taught once per academic year and during each period of its provision, the precourse and post-course tests are conducted. Furthermore, the survey regarding electronic services acceptance is administered before the course and after its completion. After the completion of the ESB course also participants' feedback on the course is collected. Relevant suggestions contained in the feedback from the students serve for further improvement of the ESB course educational process in the following years.

In the course of Electronic Services in Banking, also the surveys were administered before the beginning of the course and after its end. Their purpose was to examine any shifts in participants' attitude towards using electronic services in banking. The survey after the course completion also contained part for the feedback on the course. This feedback is the source for improvements tips in the educational process of the ESB course in the following years of its provision.

Both surveys within the 2021 iteration of the ESB course were performed in electronic form using a Google Docs questionnaire distributed via LMS Moodle to the students of the ESB course. During the 
2021 course 137 usable questionnaires were gathered, which is over 95 percent of participants. That shows a very high return rate of the questionnaires, even if we take into account that both the course and the surveys were conducted completely online.

Over 61 percent of surveys' respondents were women. This ratio nearly reflects the composition of students by gender within the course. When considering the age composition of respondents, the most of students were from the age group of 18 to 25 years old (over 86 percent), which is the typical age of students in full-time study form. Respondents of higher age were mainly students of the part-time form of study. Also, the size of the municipality of residence was inquired as it might have an impact on the availability of broadband internet connection in local conditions. Fast and stable internet connection is an important condition for use of multiple electronic services in banking. The availability of fast internet in small municipalities might be lower in Slovak conditions [31]. This situation might have concerned 11.7 percent of respondents in our study. At the same time, it could affect student's ability to attend online classes, but no such problems were detected during pandemic iterations of The ESB course. Table 2 contains demographic data of the survey respondents.

Table 2. Demographic data of participants in pre-course and post-course surveys

\begin{tabular}{||lcc||}
\hline \multicolumn{1}{|c}{ Gender } & Count & Percentage \\
Male & 53 & 38.7 \\
Female & 84 & 61.3 \\
Total & 137 & 100 \\
Age & & \\
$18-25$ & 118 & 86.1 \\
26-35 & 17 & 12.4 \\
36 and over & 2 & 1.5 \\
Residence size & & \\
Large-sized municipality (over 100k residents) & 80 & 58.4 \\
Medium-sized municipality (5k to 100k residents) & 41 & 29.9 \\
Small-sized municipality (below 5000 residents) & 16 & 11.7 \\
\hline
\end{tabular}

The same questions were asked in the pre-course and the post-course surveys. The following data are results of the pre-course survey. Almost 86 percent adduced using some form of electronic banking before the ESB course. The most used form of electronic banking among the respondents was mobile banking with almost 74 percent usage. Almost 60 percent of the participants are users of internet banking, and most of them use both abovementioned forms of electronic banking.

The respondents who did not indicate using electronic banking were asked for the reasons. Almost 9 percent indicated that they do not trust electronic banking due to the perceived low security of these services and other safety concerns. Over 4 percent adduced did not have any current account or did not use any banking service yet. This group of respondents was composed of young students having only cash income in form of pocket money from their family. Around one percent of the survey participants uses only the services of traditional brick-and-mortar bank branches.

Subsequently, the frequency of electronic banking services usage was investigated. Around 64 percent of participants use electronic banking on the monthly basis. Over 22 percent of respondents use electronic banking at least once per week. Approximately 81 percent admitted preference of electronic payment (if available) over cash payment. Almost 51 percent of participants consider the offer of electronic banking services in a particular bank as an important factor of banking services provider selection.

Furthermore, the investigation of the safety of the usage of electronic banking followed. When preference of authorization forms was examined, almost 62 percent of users adduced preference of static codes (passwords, PINs) if it was an available option. Over 26 percent preferred biometric authorization and less than 14 percent preferred dynamic codes (e.g. tokens, one-time password generators). None of the respondents stated a preference for digital signature. These results show a high preference for static less secure authorization elements among respondents.

The survey respondents tried to indicate the most secure authorization element. Over 37 percent denoted biometric elements and 21 percent dynamically generated codes. Still, almost 33 percent adduced static codes as the most secure form of authorization. The rest ( 9 percent) indicated digital signature. These results suggest that participants before the course could not identify secure elements properly. Our respondents also expressed their attitude towards digital signature usage. Over 60 percent denoted it as appropriate for e-government applications. Almost 36 percent consider digital 
signature suitable for confirmation of electronic documents (e.g. when communicating with banks or public authorities).

The participants further identified worries when using electronic banking. Almost 70 percent of respondents are afraid of third-party attacks on their electronic banking, over 41 percent are worried about the possible technical errors in electronic banking and 12 percent are concerned about possible fraud by the banking institution employees. On the other hand, the protection against viruses and other harmful software as crucial was identified by 97 percent of respondents. Almost 58 percent of respondents did not have knowledge about the rules of safe electronic banking usage or did not adhere to them.

The following results were recorded in the survey after the ESB course completion and compared with the results of the pre-course survey. The same respondents participated in the survey as in the precourse survey.

After the course completion, over 92 percent of respondents adduced usage of any electronic banking form (an increase by 6 percent). Almost 89 percent of participants used mobile banking and 65 percent used internet banking. Approximately 10 percent of respondents indicated that they started to use more secure forms of authorization in their electronic banking (changes from static codes to dynamically generated or biometrics) during the course. Just one percent of participants still denoted distrust of electronic banking services (a distinctive decrease from 9 percent in the pre-course survey).

Over 77 percent of participants use electronic banking every month after the ESB course completion. The course graduates' concerns about secure usage of electronic banking have decreased in all cases. Apprehension of third-party attacks decreased from 70 percent to 48 percent. Concerns of technical errors in electronic banking applications dropped from 41 percent to the level of 28 percent. Less than 30 percent of respondents still admitted not adhering to the safety rules for electronic banking usage (a substantial decrease from 58 percent). This comparison of post-course to the pre-course levels designates positive changes in knowledge and attitude of the ESB course participants.

As an integral part of the post-course survey also participants' feedback on the ESB course was gathered. In total 92 percent of respondents were satisfied with the ESB course (almost 59 percent were very satisfied). Students (79 percent) exalted in their answers mainly seamless transition to fully online educational process enforced due to antipandemic measures valid in the country. The course participants (48 percent of responses) also welcomed the emphasis on the security of electronic banking and they indicated the improvement of their safety behavior when using electronic banking. Almost 40 percent of respondents also highlighted the possibility to expand their knowledge in the field of electronic banking through the preparation (and presentation) of essays. Slightly less than 24 percent of students even stated that participation in the ESB course encouraged them to try out some new electronic service in banking.

The majority of students (over 54 percent) suggested leaving out any presentation of older forms of electronic banking, but over 20 percent of students, on the other hand, welcomed the opportunity to get acquainted with the development of electronic banking over time. Several participants (almost 17 percent) would welcome the practical presentation of the newest technologies (e.g. biometric authorization). Multiple of those were presented in the form of multimedia sources as they are not supported by the software available to our institution. Some of these technologies were demonstrated on the real-life electronic banking services and students were encouraged to at least try them by themselves. Many of these suggestions are planned for incorporation in the next periods of the ESB course provision.

\section{Conclusion}

The course of Electronic Services in Banking (ESB) acquaints its participants with the area of electronic services in banking in both theoretical and practical ways. Their attendance in the course supports their adoption of electronic banking services. The ESB course is amended and improved in each year of its provision to better reflect the rapidly changing world of electronic services in banking. The ESB course participants gain during the course also practical experience with multiple electronic services in banking using various technical means (e.g. multimedia, emulators, virtual bank, certification authority, etc.). The Covid-19 pandemic prevention measures did not disturb the provision of the course in 2020 and 2021. The efficiency of the educational process in the ESB course was evaluated to compare its pre-pandemic and pandemic iterations.

The efficiency of education within the ESB course was measured using absolute gain, relative gain, and class average normalized gain achieved between the pre-course and the post-course test results. The comparison was conducted during the pre-pandemic years of 2017, 2018, and 2019 and pandemic 2020 and 2021 iterations of the ESB course. In all investigated years effective levels (above 30\%) of class average normalized gain were detected.

The investigation of educational efficiency was supplemented with the comparison of e results of precourse and post-course surveys, which indicated 
multiple positive changes in student's knowledge in the area of electronic services in banking. Furthermore, an increase in participants' acceptance of electronic services in banking was detected. In addition to that, the feedback from the students was gathered showing that the ESB course was valuable for them. Their feedback also served as a source for continual development of the educational process within the course of Electronic Services in Banking.

\section{Acknowledgements}

This research was supported by the national project "Decision Support Systems and Business Intelligence within Network Economy" (Contract No. 1/0201/19) funded by Grant Agency for Science; Ministry of Education, Science, Research and Sport of the Slovak Republic.

\section{References}

[1]. BV, S. E. (2013). Electronic banking: The ultimate guide to business and technology of online banking. Springer Science \& Business Media. https://doi.org/10.1007/978-3-322-86627-1

[2]. Joshi, V. C. (2020). Digital finance, bits and bytes: The road ahead. Springer Nature.

[3]. Moodle.org. (2021). About Moodle., Retrieved from: https://docs.moodle.org/311/en/About_Moodle\#Built for learning.2C globally [accessed: 23 May 2021].

[4]. Pal'ová, D. (2016, May). Experience with usage of LMS Moodle not only for the educational purposes at the educational institution. In 2016 39th International Convention on Information and Communication Technology, Electronics and Microelectronics (MIPRO) (pp. 901-906). IEEE.

[5]. Vejačka, M. \& Štofa, T. (2017). Influence of security and trust on electronic banking adoption in Slovakia. E\&M Economics and Management, 20(4), 135-150. https://doi.org/10.15240/tul/001/2017-4-010.

[6]. Bucko, J. (2017). Security of smart banking applications in Slovakia. Journal of theoretical and applied electronic commerce research, 12(1), 42-52. https://doi.org/ 10.4067/S0718-18762017000100004.

[7]. Alsajjan, B., \& Dennis, C. (2010). Internet banking acceptance model: Cross-market examination. Journal of business research, 63(9-10), 957-963. https://doi.org/10.1108/IJBM-05-2017-0082.

[8]. Schierz, P. G., Schilke, O., \& Wirtz, B. W. (2010). Understanding consumer acceptance of mobile payment services: An empirical analysis. Electronic commerce research and applications, 9(3), 209-216. https://doi.org/10.1016/j.elerap.2009.07.005.

[9]. Geetha, K. T., \& Malarvizhi, V. (2011). Acceptance of e-banking among customers (An empirical investigation in India). Journal of management and science, 2(1), 1-9.

[10]. EJBCA. (2021). EJBCA Community Open Source PKI Certificate Software. Retrieved from: https://www.ejbca.org [accessed: 15 June 2021].
[11]. Bucko, J., Kakalejčík, L., \& Nastišin, L. (2015). Use of smartphones during purchasing process. In Central European Conference in Finance and Economics (CEFE2015), Technical University of Košice (pp. 9197).

[12]. Valle, A. G. R. M. D., \& Gomes, R. C. (2014). Analyzing the importance of financial resources for educational effectiveness: The case of Brazil. International Journal of Productivity and Performance Management, 63(1), 4-21. https://doi.org/10.1108/IJPPM-08-2012-0085.

[13]. Scheerens, J. (2016). Educational effectiveness and ineffectiveness. A critical review of the knowledge base, 389.

[14]. Bowman, N. A. (2010). Can 1st-year college students accurately report their learning and development?. American Educational Research Journal, 47(2), 466-496.

[15]. Vermunt, J. D., Ilie, S., \& Vignoles, A. (2018). Building the foundations for measuring learning gain in higher education: a conceptual framework and measurement instrument.Higher Education Pedagogies, 3(1), 266-301. https://doi.org/10.1080/23752696.2018.1484672.

[16]. Evans, C., Kandiko Howson, C., \& Forsythe, A. (2018). Making sense of learning gain in higher education. Higher Education Pedagogies, 3(1), 1-45. https://doi.org/10.1080/23752696.2018.1508360.

[17]. Willetts, D. (2017). A University Education. Oxford: Oxford University Press, p. 469. https://doi.org/10.1093/oso/9780198767268.001.0001

[18]. Polkinghorne, M., Roushan, G., \& Taylor, J. (2017). Considering the marketing of higher education: the role of student learning gain as a potential indicator of teaching quality. Journal of Marketing for Higher Education, 27(2), 213-232. https://doi.org/10.1080/08841241.2017.1380741.

[19]. Cunha, J. M., \& Miller, T. (2014). Measuring valueadded in higher education: Possibilities and limitations in the use of administrative data. Economics of Education Review, 42, 64-77. https://doi.org/10.1016/j.econedurev.2014.06.001.

[20]. Colt, H. G., Davoudi, M., Murgu, S., \& Rohani, N. Z. (2011). Measuring learning gain during a one-day introductory bronchoscopy course. Surgical endoscopy, 25(1), 207-216.

https://doi.org/10.1007/s00464-010-1161-4.

[21]. Hake, R. R. (2007). Should We Measure Change? Yes! white paper, Retrieved from: http://www.physics.indiana.edu/ hake/MeasChangeS. pdf. [accessed: 20 June 2021].

[22]. Meltzer, D. E. (2002). The relationship between mathematics preparation and conceptual learning gains in physics: A possible "hidden variable" in diagnostic pretest scores. American journal of physics, 70(12), 1259-1268. https://doi.org/10.1119/1.1514215.

[23]. McGrath, C., Guerin, B., Harte, E., Frearson, M., \& Manville, C. (2015). Learning gain in higher education (p. 7). Santa Monica, CA: RAND Corporation. $\quad$ https://doi.org/10.7249/RR996. 
[24]. Prather, E. E., Rudolph, A. L., Brissenden, G. \& Schlingman, W.M. (2009). A national study assessing the teaching and learning of introductory astronomy. Part I. The effect of interactive instruction. American Journal of Physics, 77(4), 320-330. https://doi.org/10.1119/1.3065023.

[25]. Epstein, J. (2009, January). The Calculus Concept Inventory new data, correlation with teaching methodology. In Joint Mathematics Meeting: 115th Annual Meeting of the American Mathematical Society (AMS) and the 92nd Meeting of the Mathematical Association of America (MAA), Washington, DC.

[26]. Hake, R. (2002). Lessons from the physics education reform effort. Conservation Ecology, 5(2). https://doi.org/10.5751/ES-00286-050228.

[27]. Wieman, C., \& Perkins, K. (2005). Transforming physics education. Physics today, 58(11), 36.
[28]. Hair Jr, J. F., Babin, B. J., Anderson, R. E., \& Black, W.C. (2019). Multivariate Data Analysis. 8th Ed. Andover: Cengage Learning EMEA.

[29]. Hake, R. R. (1998). Interactive-engagement versus traditional methods: A six-thousand-student survey of mechanics test data for introductory physics courses. American journal of Physics, 66(1), 64-74. https://doi.org/10.1119/1.18809.

[30]. Prather, E. E., Rudolph, A. L., \& Brissenden, G. (2009). Teaching and learning astronomy in the $21 \mathrm{st}$ century. Physics Today, 62(10), 41-47. https://doi.org/10.1063/1.3248478.

[31]. European Commission. (2021). Digital single market. Country information Slovakia.

Retrieved from: https://ec.europa.eu/digital-singlemarket/en/country-information-slovakia. [accessed: 01 August 2021]. 